\title{
Cytological Studies in Some Male Sterile Jowars (Sorghum vulgare, Pers) and Their Maintainers and Restorers
}

\author{
M. N. Narkhede, B. A. Phadnis, and M. V. Thombre \\ College of Agriculture, Nagpur, India
}

Received February 6, 1967

Different high yielding hybrid jowar (Sorghum vulgare, Pers) varieties are cultivated extensively in this country. The majority of the varieties are produced by using m.s. C.K. 60 , as the female parent with suitable male combiners like I.S. 84 and I.S. 3691 . At the Agricultural College, Nagpur, the cytoplasmic-genetic male sterility of this line m.s. C.K. 60 (A-385) is transferred to a local variety, Improved Saoner (Joglekar and Deshmukh 1963 ) and the new male sterile line M.S. 22-5-16 so evolved, is being used as the female parent for the production of commercial hybrid seed.

Stephens and Holland (1954) while studying the cytoplasmic male sterility for hybrid seed production in jowar have stated that male sterility in certain combinations was caused by interaction between Milo cytoplasm and Kafir nuclear genes. While studying the stage of pollen grain degeneration in male sterile grain 'Sorghum', Maunder and Pickett (1959) have reported that meiosis in the male sterile grain Sorghum appeared to be normal, but after the pollen grains were partially formed they tended to shrivel and the anthers reduced in size and lacked viable pollens prior to dehiscence. Singh and Hadley (1961) have stated that there was a possible association of the nonviable character of pollen grains with the nutritive role of tapetum in m.s. C.K. 60. According to these workers meiosis was found to be normal in the m.s. plants, but the pollen grains deteriorated after their formation. The tapetum in such anthers did not deteriorate and release the food material necessary for the normal development of the pollen grains. Shambulingappa and Magoon (1963) have also reported normal meiosis in m.s. C.K. 60. However they did not report the stage at which the pollen degeneration took place. The pollen grain abortion in the male sterile lines was also studied in the plants like sugar-beets (Ernst Artswager 1947); maize (Rhoades 1933), Wheat (Fukasawa 1954, 1956), tomato (Lesly and Lesly 1939) etc. and similar observations were reported. The present investigations were, therefore, undertaken with a view to study the meiosis in the different fertile parental varieties and male sterile lines and the stage of pollen abortion in the newly developed M.S. line M.S. 22-5-16.

\section{Material and methods}

For the study of meiosis in PMC's, development of pollen grains and role of tapetum in the pollen abortion, the following varieties of jowar were used.

$\begin{array}{lcr}\text { Fertiles } & \text { Male steriles } & \text { Maintainers } \\ \text { Redar } & \text { m.s. C.K. } 60 \text { (A.385) } & \text { m.s. C.K. } 60 \text { (B. }\end{array}$

Redar m.s. C.K. 60 (A.385)

m.s. C.K. 60 (B. 385)

M 35-1

m.s. 22-5-16

m. 22-5-16.

Dodania

Vidul

Meiosis in pollen mother cells was studied from the flower buds of very young panicles, fixed in Carnoy's fluid $(6: 3: 1)$ and after 24 hours stored in $70 \%$ alcohol for preservation.

The anthers were smeared in $1 \%$ Acetocarmine. Observations on the chromosome behaviour were made using oil immersion objective $100 \times$, N.A. 1.3 and compensating eye piece $10 \times$. 


\section{Results}

Meiotic studies in the fertile parents and maintainers. The meiosis was studied in the four fertile male parents viz. Redar, M 35-1, Dodania and Vidul and the maintainer parent viz. M 22-5-16. The meiosis in the maintainer parent B 385 has been already reported by Singh and Hadley (1961) and their observations are confirmed in the present studies. In all these parents the pachytene chromosomes showed differential stainability. The regions close to the centromere appeared to be heavily stained with acetocarmine whereas the distal ends were stained lightly (Fig. 1). From diplotene to diakinesis 10 well distributed bivalents were observed in all the varieties. On an average 18 to 20 chiasmata were recorded in each of the varieties. The first and the second division segregation was found to be normal in all the varieties except the variety Vidul. In this variety at metaphase I more than 10 bivalents were observed in certain nuclei. The number of bivalents in such cells varied between 12 to 16 (Fig. 2). The tetrad formation and pollen grain development were normal.

Meiosis in the male sterile parents. The details of meiosis upto tetrad formation in the male sterile parent A 385 has been reported by Singh and Hadley (1961)

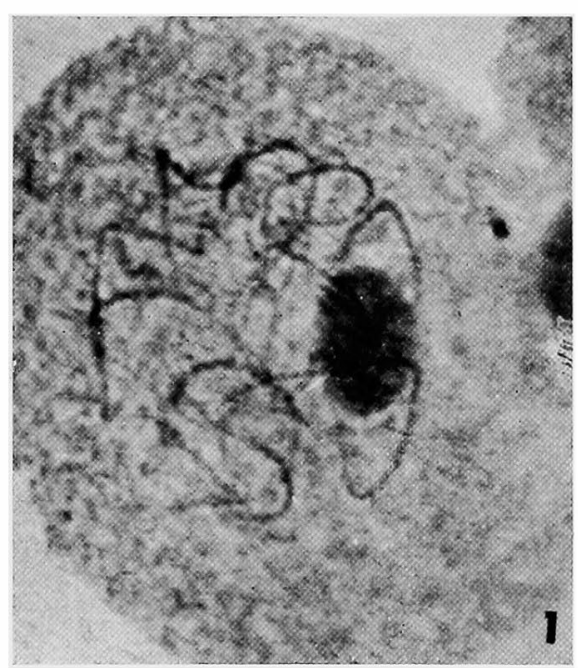

Fig. 1. Pachytene chromosomes showing differentially stained regions in M. 35-1. $\times 1000$. and Shambulingappa and Magoon (1963). These workers have observed normal meiosis. These observations were confirmed in cur studies. In case of m.s. 22-5-16, the pachytene chromosomes showed differential stainability as in the case of other varieties. The early stages of meiosis were normal and showed 10 bivalents with a chiasma frequency from 19 to 20 per cell. At metaphase I however, more than 10 pairs of bivalents i.e. from 12 to 16 bivalents were observed in $4 \%$ of the cells studied (Fig. 3). Anaphasic separation was normal except in rare cases where 14-14 distribution was observed (Fig. 4). Similarly laggards were also observed at anaphase I (Fig. 5). It was also observed in certain cells of this variety that the cytokinesis took place after the first division along the axis joining the two nuclei.

Degeneration of pollen-grains in the male sterile jowar m.s. 22-5-16.

The successive stages of anther and pollen grain development were studied by observing the fixed anthers of varying sizes in acetocarmine. In the anthers of fertile parents the tapetal cells had one to two nuclei and these cells appeared normal and turgid till tetrad formation. But in the anthersacs containing developed pollen grains the tapetal cells appeared shrivelled 
and degenerated (Fig. 6). In the male sterile plants A. 385 and m.s. 22-5-16 the tapetal cells appeared normal and occasionally with two nuclei till the tetrad formation (Fig. 7). The pollen grain degeneration in A 385 took place before the first mitotic division. In m.s. 22-5-16 the pollen grain degeneration
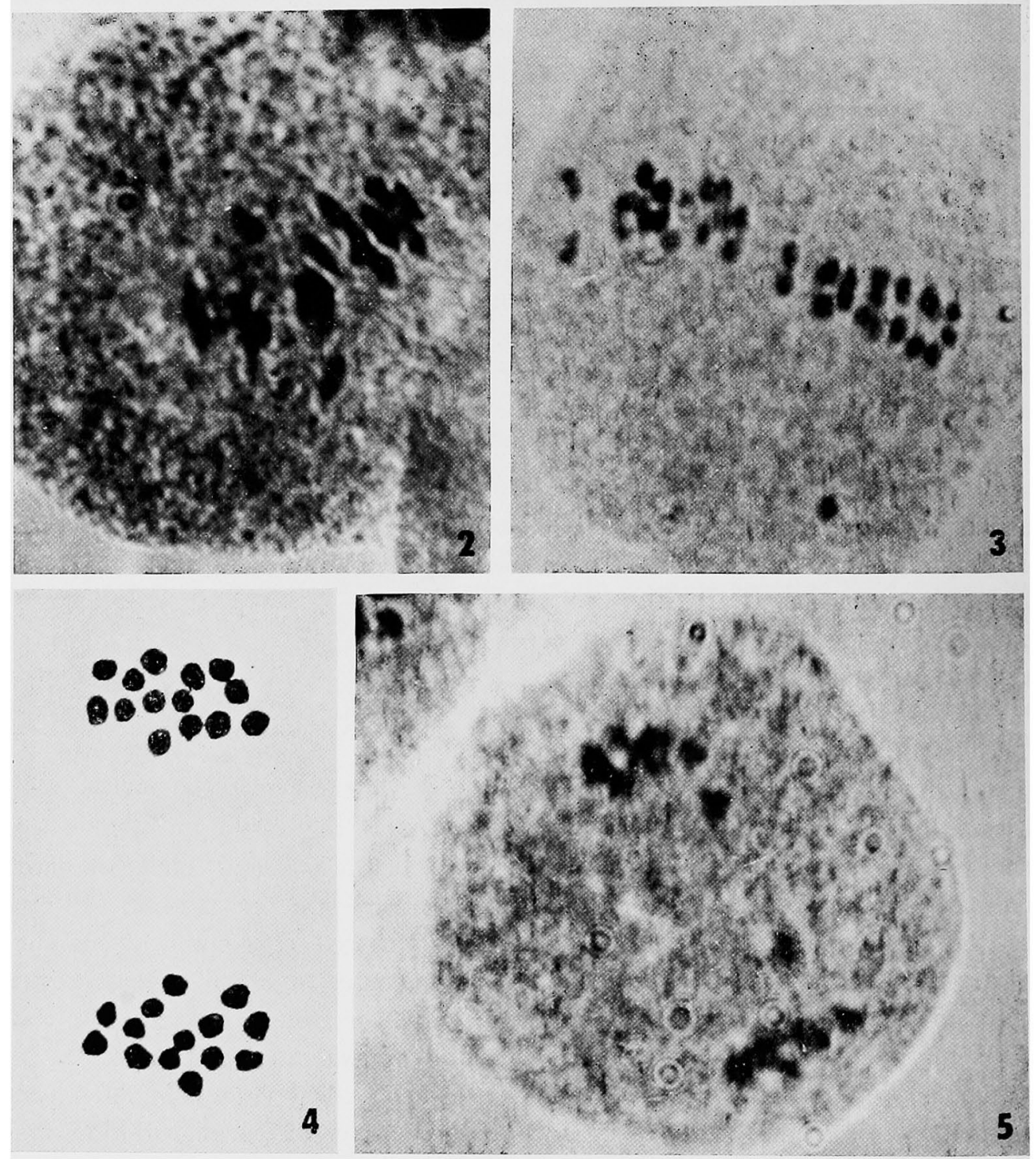

Figs. 2-5. $\times 1000.2$, metaphase I showing more than 10 bivalents in Vidul. 3, metaphase I showing more than 10 bivalents in m.s. 22-5-16. 4, camera lucida drawing showing regular separation of chromosomes at anaphase I in a PMC's. having 14 bivalents at metaphase I in m.s. 22-5-16. $1000 \times$. 5, anaphase I showing laggard chromosomes in m.s. 22-5-16.

took place mostly before the first mitotic division but a few pollen grains degenerated after completion of the first mitotic division (Fig. 8). In further stages of both these m.s. types the pollen grains appeared shrivelled and degenerated (Fig. 9). The tapetal cells in these anthers were normal, turgid and occasionally with two nuclei. 


\section{Discussion}

Studies on meiosis in pollen mother cells in Sorghum vulgare Pers have been made by a number of workers (Kuwada 1919, Garber 1944, Hadley 1953, Endrizzi 1957, Sharma and Bhattacharjee 1957, and Magoon et al. 1963). The above workers have reported $2 \mathrm{n}=20$ as somatic chromosome number in this sps. In the present investigation all the varieties viz. Redar, M 35-1, Dodania and Vidul belonging to $S$. vulgare Pers were found to have $2 \mathrm{n}=20$ chromosomes.
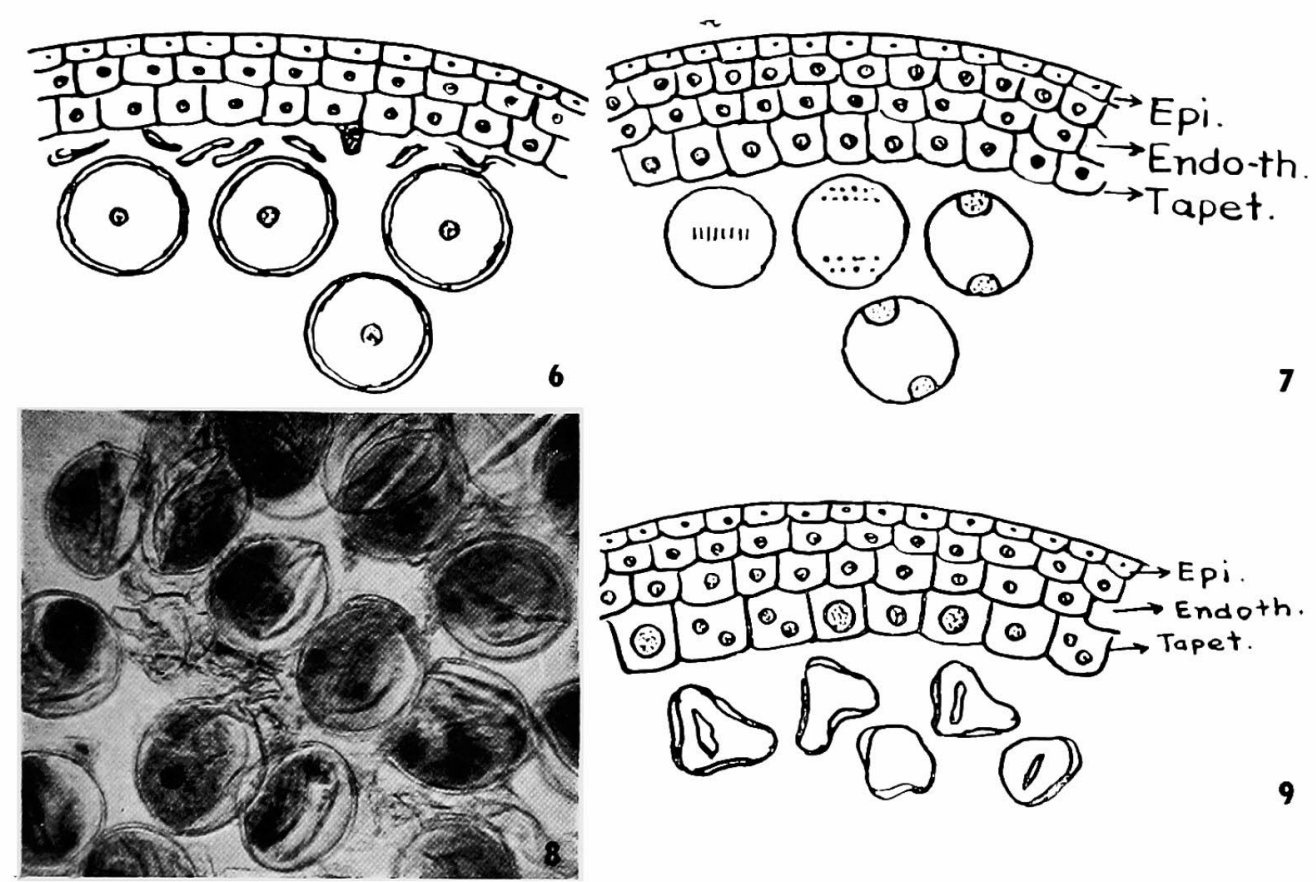

Figs. 6-9. 6, degeneration of tapetum and normal development of pollen grains in fertile Jowar Vidul. $\times 800$. 7 , normal development of tapetum in pre-meiotic stages in male sterile Jowar m.s. 22-5-16. 8, pollen grains showing one or two nuclei in m.s. 22-5-16. $\times 360$. 9, persistant tapetum and degeneration of pollens in male steriles Jowar m.s. 22-5-16. $\times 800$.

The differential stainability of the pachytane chromosomes observed in the present studies is a characteristic found in all Eusorghums so far studied (Longley 1932, Garber 1944, Hadley 1953, Magoon et al. 1961, 1963 and 1964, Venkateshwarlu and Reddi 1956). Similarly the average number of chiasmata observed per cell by Magoon et al. (1961 and 1963) have been confirmed in all the varieties studied. Huskins and Smith (1934) and Chin (1946) in diploid Sorghum revealed the presence of ten bivalents usually and quadrivalents and sexivalents occasionally. In the present report usually ten bivalents were observed, however, in a few PMC's of the variety Vidul more than ten bivalents were observed. This might be due to cytomixis.

The studies of Maunder and Pickett (1959) on cytological aspects of 
cytoplasmic-genetic male sterile grain Sorghum revealed normal meiosis. Shambulingappa and Magoon (1963) have reported similar observations in m.s. C.K. In the present investigation also the meiosis in PMC's. of A 385 was found normal. In m.s. 22-5-16 85\% of the PMC's studied showed 10 bivalents at diakinesis and metaphase I. Anaphasic separation of chromosomes was found normal in these PMC's. The rest of the cells studied were with more than 10 bivalents at metaphase $I$, two trivalents and seven bivalents and laggard chromosomes at anaphase I.

The presence of more than ten bivalents in the PMC must be due to the transfer of chromatin material from the adjacent pollen mother cells. This phenomenon of cytomixis has been reported in many plant genera (Mc Clintock 1929) in Zea mays, Sarvella (1958) in Gossypium and Kamara (1961) in Hordeum. According to Linnert (1955) cytomixis can arise due to defective squashing, but according to Kamara (1961), it can arise naturally. In the present work cytomixis was observed consistently in many different random plants of m.s. 22-5-16 and as such it can be said that it was not a chance occurrence or due to defective squashing technique.

Laggards at anaphase I may be due to delay in separation of chromosome to the two poles, whereas the chromosome bridge formation may be due to a small inversion or may be due to stickiness of the chromosomes as no fragments could be seen.

The pollen grains of A 385 were found shrivelled shortly before the first mitotic division; whereas in m.s. 22-5-16, in a few cases pollen grain degeneration took place at a little later stage i.e. after completing the first mitotic division and in rest of the cases before the first mitotic division as in the case of A 385. This difference in the behaviour of the m.s. 22-5-16 in respect of the degeneration of pollen grains suggests that there is a possibility that the pollen degeneration in these lines might be taking place at different stages up to complete development of male gametophyte. Since the line m.s. 22-5-16 is in the developing stage and would take some time to get cytologically and genetically stabilized, it is likely that some of the minor genes or modifiers might be acting in bringing about the degeneration of pollen grains at different stages.

The rapid and uniform degeneration of pollen grains in the different cytoplasmic genetic male sterile lines is explained on the basis of interaction between a particular sterile cytoplasm and recessive nuclear genes (Stephens and Holland 1954, Joglekar et al. 1963). It would be interesting to know any other developments aiding pollen degeneration in such plants with specific cytoplasm and nuclear genes. Thus Ernst Artswager (1947) in sugar beet and Singh and Hadley (1961) in m.s. C.K. 60 have reported the specific role of tapetum layer in the anther sacs of male sterile plants. According to above workers the tapetal layer in male steriles does not degenerate after the development of microspores from the PMC's and thus probably bring about the 
starvation in them. The studies made in this respect in the strains A 385 and m.s. 22-5-16 have confirmed these observations.

Acknowledgments: Our sincere thanks are due to Shri B. G. Ghawghawe, Professor of Botany, College of Agriculture, Nagpur for providing necessary facilities for these investigations.

\section{Bibliography}

Artswager, E. 1947. Pollen degeneration in male sterile sugar beets with special reference to tapetal plasmodium. Jour. Agr. Res. $75(7 \&$ \&): 191-197.

Chin, T. C. 1946. The cytology of polyploid Sorghum. Amer. Jour. Bot. 33: 611-614.

Endrizzi, J. E. 1957. Cytological studies of some sps. and hybrids in the Eusorghum. Bot. Gaz. 119: 1-10

Fukasawa, H. 1954. Appearance of male sterile durum in substitution crosses. Cytologia 18: $167-175$.

- 1956. Cyto-histological investigation of pollen degeneration in anthers of male sterile plants. Cytologia 21: 97-103.

Garber, E. D. 1944. A cytological study of the genus Sorghum. Sub. sect. Para and Eusorghum. Amer. Nat. 78: 89-93.

Hadley, H. H. 1953. Cytological relationship between Sorghum vulgare and S. halepense. Agro. Jour. 45: 139-143.

Huskins, C. L. and Smith, S. G. 1934. A cytological study of the genus Sorghum II. The meiotic chromosomes. Jour. Genet, 28: 387-395.

Joglekar, R. G. and Deshmukh, N. Y. 1963. Cytoplasmic male sterile strains in jowar (S. vulgare) suitable for exploitation of heterosis. Nagpur Agr. Coll. Mag. 34(1-4): $31-52$.

Kamara, O. P. 1960. Chromosome extrusion and cytomixis in PMC's of Hordeum. Hereditas 46: $596-600$.

Kuwada, H. J. 1919. Journ. Coll. Sci. 39, 1: 148.

Lesly, J. W. and Lesly, M. M. 1939. Unfruitfulness in tomato caused by male sterility. Jour. Agr. Res. 58: 621-630.

Linnert, G. 1955. Der Züchter 25: 237-241.

Longley, A. E. 1932. Chromosomes in the grass Sorghums Jour. Agr. Res. 44: 317-321.

Magoon, M. L. 1961. Cytology of some Eussrghums. Genetica Iber. 13: 120-144.

-, Manchanda, P. L. and Ramana, M. S. 1964. Cytological and morphological studies in the genus Srghum. Cytologia 29: 42-60.

Maunder, A. B. and Pickett, R. C. 1959. The genetic inheritance of cytoplasmic genetic male sterility in grain Sorghum. Agro. Jour. 5(1): 47-49.

McClintock, B. 1929. A cytological and genetical study of triploid maize. Genetics 14: $180-222$.

Rhoades, M. M. 1933. The cytoplasmic inheritance of male sterility in Zea mays. Jour. Genet. 27: 71-93.

Sarvella, P. 1958. Cytomixis and the loss of chromosomes in meiotic and somatic cells of Gossypium. Cytologia 23: 14-24.

Shambulingappa, K. G. and Magoon, M. L. 1963. Cytomorphological studies in the genus Sorghum. Ind. Jour. Genet. 275-289.

Sharma, A. K. and Bhattacharjee, D. 1957. Chromosome studies in the genus Sorghum. Cytologia 22(3/4): 287-311.

Singh, S. P. and Hadley, H. H. 1961. Male sterility in Sorghum. Pollen abortion in cytoplasmic male sterile Sorghum. Crop. Sci. 1(6): 430-432.

Stephens, J. C. and Holland, R. F. 1954. Cytoplasmic male sterility for hybrid seed production. Agro. Jour. 46: 20.

Venkateshwarlu, J. and Reddi, V. R. 1956. Morphology of pachytene chromosomes and meiosis in Sorghum-Eusorghum. Jour. Ind. Bot. Soci. 36: 344-356. 